\title{
Precipitation of calcium carbonate in the presence of urea at $293 \mathrm{~K}$ and $343 \mathrm{~K}$
}

\author{
Katarzyna Białowicz, Urszula Kiełkowska \\ Nicolaus Copernicus University, Faculty of Chemistry, 7 Gagarin Street, 87-100 Toruń, Poland, e-mail: fiodor@chem.umk.pl
}

\begin{abstract}
The results of the precipitation of calcium carbonate from a waste post-distillation liquid (DS) and a sodium bicarbonate saturated solution - both from the Solvay method - in the presence of urea are presented. The investigation was carried out at $293 \mathrm{~K}$ and $343 \mathrm{~K}$. Reagent dosage times of 1, 5, 10, 20 and $30 \mathrm{~min}$, and urea concentrations of 5,6 and $10 \mathrm{~mol} / \mathrm{dm}^{3}$ were applied. The granulometric composition, the values of bulk and packing densities and the absorptiveness sorption of water and paraffin oil from the obtained calcium carbonate were investigated.
\end{abstract}

Keywords: calcium carbonate, precipitation, sodium bicarbonate, urea, utilization.

\section{INTRODUCTION}

The intensive development of civilization is closely associated with the generation of large amounts of different types of waste that are hazardous to the environment and human health. The growing threat has become so great that all developed countries have made major efforts to remove these hazards, or at least minimize them.

In addition to its unquestionable advantages, the Solvay method for the production of sodium carbonate also has many disadvantages, including environmental pollution associated with the generation of large amounts of liquid and solid waste. This waste remains unmanaged and is discharged into natural bodies of water or else is collected near plants at waste heaps called "white seas".

The present study aims to obtain precipitated calcium carbonate with properties that can be used in different branches of industry while utilizing the waste products of the soda industry. The use of waste materials for the production of a useful product provides an invaluable advantage in terms of environmental protection ${ }^{\mathbf{1 - 1 2}}$.

Currently, calcium carbonate is used in many areas of technology and industry. Depending on the source, the production method and the quality of the resulting product, it is used in paper, rubber, food, cosmetics, the construction industry and agriculture. It is widely applied in pharmacy as a polishing and neutralizing agent. It can be a carrier for drugs and plant protection products, a filler for plastomers and elastomers, or a filler for paints and coatings.

Natural calcium carbonate used in the construction industry and many other areas has been processed and modified for years. Calcium carbonate processing is based on grinding, scraping, dewatering, drying and loosening. However, despite the use of quality improvement procedures, the resulting product often does not meet the requirements of many industries.

Therefore, natural calcium carbonate is replaced with a synthetic product.

Due to the differing requirements of industries, synthetic calcium carbonate is available in many varieties with different purities, crystallographic structures, particle sizes and shapes of the crystals. This has a definite impact on its later use. Depending on the need in question, the resulting product may be modified with various compounds (e.g., surfactants ${ }^{13-17}$ ). It has also been demonstrated that certain organic compounds and polymers can affect the crystallization of inorganic salts, which determines the quality of the product.
The introduction of urea to the calcium carbonate precipitation process was inspired by numerous reference works describing the interactions of $\mathrm{CO}\left(\mathrm{NH}_{2}\right)_{2}$ with inorganic salts in aqueous solutions ${ }^{18-21}$.

The aim of this study is to obtain precipitated calcium carbonate as a result of the reaction of calcium ions from a waste post-distillation liquid (DS) via the Solvay method with bicarbonate ions derived from a sodium bicarbonate solution, in an environment with high concentrations of urea.

\section{EXPERIMENT}

\section{Material}

A post-distillation liguid (DS), sodium bicarbonate (Inowrocławskie Zakłady Chemiczne Janikosoda S.A.) and $\mathrm{CO}\left(\mathrm{NH}_{2}\right)_{2}$ (purity of $99.5 \%$, POCh Gliwice S.A., Poland) were used for all the experiments.

The average composition of the DS is shown in Table 1. The concentration of a saturated solution of sodium bicarbonate ranged from $1.158 \mathrm{~mol} / \mathrm{dm}^{3}$ to $1.226 \mathrm{~mol} / \mathrm{dm}^{3}$.

Table 1. Average composition of the post-distillation liquid (DS)

\begin{tabular}{|l|c|}
\hline Component & $\begin{array}{c}\text { Concentration } \\
{\left[\mathrm{g} / \mathrm{dm}^{3}\right]}\end{array}$ \\
\hline $\mathrm{Ca}^{2+}$ & 39 \\
\hline $\mathrm{Fe}^{3+}, \mathrm{Fe}^{2+}$ & $3.8 \cdot 10^{-5}$ \\
\hline $\mathrm{Cl}^{-}$ & 105 \\
\hline $\mathrm{SO}_{4}{ }^{2-}$ & 0.69 \\
\hline
\end{tabular}

\section{Experimental Procedure}

Tests for the calcium carbonate precipitation process were carried out at temperatures of $293 \mathrm{~K}$ and $343 \mathrm{~K}$ by dispensing substrates into $250 \mathrm{~cm}^{3}$ of the urea solution at concentrations of 5,6 and $10 \mathrm{~mol} / \mathrm{dm}^{3}$. The process was carried out using a variable reagent, dispensing time: 1, 5, 10, 20 and $30 \mathrm{~min}$. The apparatus used in the tests is presented in an earlier work ${ }^{22}$. The reaction mixture was stirred at a constant speed of $500 \mathrm{rpm}$.

$400 \mathrm{~cm}^{3}$ of the DS and a corresponding amount of $\mathrm{NaHCO}_{3}$ were used for the precipitation of each portion of the calcium carbonate, in accordance with the equation: $\mathrm{CaCl}_{2}+2 \mathrm{NaHCO}_{3} \rightarrow \mathrm{CaCO}_{3}+2 \mathrm{NaCl}+\mathrm{H}_{2} \mathrm{O}+\mathrm{CO}_{2}$

Specific volumes of the substrates were fed to feed the (upper) tanks, where they were thermostated to reach the desired temperature, and then the DS and $\mathrm{NaHCO}_{3}$ solution was dosed, at a specific time, to the main thermostated (lower) reactor, containing $250 \mathrm{~cm}^{3}$ 
of a suitable concentration of urea. After filtering from the mother liguid, the washing away of the chloride ions and drying at $378 \mathrm{~K}$, the resulting calcium carbonate was then subjected to a physical and chemical analysis.

The basic physical and chemical parameters of the resulting calcium carbonate were determined, namely the bulk density, the packing density, the water and paraffin oil absorbing capacities, and the crystallographic form of the resulting crystals. The packing density was measured using Erweka's tester SVM 202, operating in accordance with the USP 2 and EP methods and DIN ISO EN 787/11.

Scanning electron microscopy images were taken and thermal and XRD analyses were performed in order to determine the morphology and microstructure of the particles.

The concentration of calcium ions in the DS was determined with the complexometric method using an EDTA solution ${ }^{23}$. The concentration of bicarbonate ions in a saturated sodium bicarbonate solution was determined with the potentiometric titration method using $0.1 \mathrm{M} \mathrm{HCl}^{24}$. Potentiometric titration was carried out using an automatic titrator 716 DMS TITRINO with a glass electrode from Methrom Switzerland. The concentration of iron(III) ions was determined with the spectrophotometric method using a double-beam spectrophotometer with a UV/VIS (U-2000 HITACHI) ${ }^{23}$. The gravimetric method was used for the determination of sulphate(VI) ions ${ }^{25}$.

\section{RESULTS AND DISCUSSION}

Precipitated calcium carbonate with specific physical and chemical properties can be obtained by the reaction of calcium ions from the liquid DS and bicarbonate ions from a saturated solution of sodium bicarbonate in the presence of various concentrations of urea, at temperatures of $293 \mathrm{~K}$ and $343 \mathrm{~K}$. Tables 2 and 3 show the results of studies on the properties of calcium carbonate, depending on the reagent dispensing time and the concentration of the urea solution in the reaction mixture. The values of the bulk and packing densities and the

Table 2. The results of the precipitation of calcium carbonate in the presence of urea at $293 \mathrm{~K}$

\begin{tabular}{|c|c|c|c|c|}
\hline \multirow{2}{*}{$\begin{array}{l}\text { Urea concentration } \\
{\left[\mathrm{mol} / \mathrm{dm}^{3}\right]}\end{array}$} & \multicolumn{2}{|c|}{$\begin{array}{l}\text { Density } \\
{\left[\mathrm{g} / \mathrm{dm}^{3}\right]}\end{array}$} & \multicolumn{2}{|c|}{ Absorbing capacities $\left[\mathrm{cm}^{3} / 100 \mathrm{~g}\right]$} \\
\hline & bulk & packing & water $H_{w}$ & paraffin oil $H_{0}$ \\
\hline \multicolumn{5}{|c|}{ reagent dosage time $\mathrm{t}=1 \mathrm{~min}$} \\
\hline 5 & 290 & 670 & 84 & 132 \\
\hline 6 & 357 & 785 & 73 & 120 \\
\hline 10 & 409 & 800 & 70 & 120 \\
\hline \multicolumn{5}{|c|}{ reagent dosage time $t=5 \mathrm{~min}$} \\
\hline 5 & 351 & 741 & 78 & 126 \\
\hline 6 & 364 & 800 & 70 & 120 \\
\hline 10 & 500 & 816 & 67 & 116 \\
\hline \multicolumn{5}{|c|}{ reagent dosage time $t=10 \mathrm{~min}$} \\
\hline 5 & 392 & 760 & 74 & 120 \\
\hline 6 & 400 & 800 & 66 & 118 \\
\hline 10 & 526 & 860 & 59 & 110 \\
\hline \multicolumn{5}{|c|}{ reagent dosage time $\mathrm{t}=20 \mathrm{~min}$} \\
\hline 5 & 417 & 769 & 74 & 118 \\
\hline 6 & 433 & 833 & 65 & 116 \\
\hline 10 & 555 & 884 & 56 & 100 \\
\hline \multicolumn{5}{|c|}{ reagent dosage time $t=30 \mathrm{~min}$} \\
\hline 5 & 434 & 870 & 63 & 116 \\
\hline 6 & 444 & 833 & 58 & 102 \\
\hline 10 & 585 & 909 & 56 & 100 \\
\hline
\end{tabular}

Table 3. The results of the precipitation of calcium carbonate in the presence of urea at $343 \mathrm{~K}$

\begin{tabular}{|c|c|c|c|c|}
\hline \multirow{2}{*}{$\begin{array}{l}\text { Urea concentration } \\
{\left[\mathrm{mol} / \mathrm{dm}^{3}\right]}\end{array}$} & \multicolumn{2}{|c|}{$\begin{array}{l}\text { Density } \\
{\left[\mathrm{g} / \mathrm{dm}^{3}\right]}\end{array}$} & \multicolumn{2}{|c|}{ Absorbing capacities $\left[\mathrm{cm}^{3} / 100 \mathrm{~g}\right]$} \\
\hline & bulk & packing & water $H_{w}$ & paraffin oil $H_{0}$ \\
\hline \multicolumn{5}{|c|}{ reagent dosage time $\mathrm{t}=1 \mathrm{~min}$} \\
\hline 5 & 230 & 588 & 98 & 144 \\
\hline 6 & 253 & 625 & 94 & 142 \\
\hline 10 & 266 & 645 & 88 & 140 \\
\hline \multicolumn{5}{|c|}{ reagent dosage time $t=5 \mathrm{~min}$} \\
\hline 5 & 238 & 625 & 88 & 132 \\
\hline 6 & 264 & 654 & 86 & 126 \\
\hline 10 & 387 & 769 & 80 & 122 \\
\hline \multicolumn{5}{|c|}{ reagent dosage time $\mathrm{t}=10 \mathrm{~min}$} \\
\hline 5 & 274 & 678 & 85 & 132 \\
\hline 6 & 294 & 714 & 78 & 114 \\
\hline 10 & 417 & 800 & 70 & 112 \\
\hline \multicolumn{5}{|c|}{ reagent dosage time $\mathrm{t}=20 \mathrm{~min}$} \\
\hline 5 & 289 & 689 & 78 & 125 \\
\hline 6 & 308 & 800 & 75 & 119 \\
\hline 10 & 435 & 869 & 65 & 116 \\
\hline \multicolumn{5}{|c|}{ reagent dosage time $\mathrm{t}=30 \mathrm{~min}$} \\
\hline 5 & 370 & 769 & 75 & 122 \\
\hline 6 & 408 & 816 & 66 & 108 \\
\hline 10 & 488 & 879 & 63 & 104 \\
\hline
\end{tabular}


water $\left(\mathrm{H}_{\mathrm{w}}\right)$ and paraffin oil $\left(\mathrm{H}_{\mathrm{o}}\right)$ absorbing capacities are presented therein.

The product obtained in the presence of urea at high concentrations $\left(5-10 \mathrm{~mol} / \mathrm{dm}^{3}\right)$ is characterized by a low packing density, not exceeding $1000 \mathrm{~g} / \mathrm{dm}^{3}$. At $293 \mathrm{~K}$, the values of the bulk density of the obtained $\mathrm{CaCO}_{3}$ are within the range $290-585 \mathrm{~g} / \mathrm{dm}^{3}$, while those of the packing density are within the range $670-909 \mathrm{~g} / \mathrm{dm}^{3}$. At $343 \mathrm{~K}$, the values of the bulk density of the obtained $\mathrm{CaCO}_{3}$ are within the range $230-488 \mathrm{~g} / \mathrm{dm}^{3}$, while those of the packing density are within the range $588-879 \mathrm{~g} / \mathrm{dm}^{3}$. Both the bulk and packing densities of the precipitated chalk increase with an increase in the concentration of urea in the reaction mixture. At both temperatures, the lowest packing density values were obtained for the $5 \mathrm{M}$ urea solution, and the highest for the $10 \mathrm{M}$ solution. This relationship was also observed at lower concentrations of urea $\left(0.5-4 \mathrm{~mol} / \mathrm{dm}^{3}\right)^{22}$. The bulk and packing densities of calcium carbonate depend largely on the time spent dispensing the raw material into the urea solution. The longer the precipitation process, the higher the values for each of the urea concentrations used.

The water absorbing capacity of the calcium carbonate surface determines the degree of agglomeration of the particles and the hydrophilic properties of the samples. The paraffin oil absorbing capacity features the hydrophobic properties of the resulting $\mathrm{CaCO}_{3}$. The relationship between the bulk and packing densities, and the water and paraffin oil absorptions of the obtained calcium carbonate is inversely proportional. At $293 \mathrm{~K}$, the water absorbing capacity of the product obtained is within the range $56-84 \mathrm{~cm}^{3} / 100 \mathrm{~g}$, while the oil absorbing capacity ranges from 100 to $132 \mathrm{~cm}^{3} / 100 \mathrm{~g}$. At $343 \mathrm{~K}$, the water absorbing capacity of the product obtained is within the range $63-98 \mathrm{~cm}^{3} / 100 \mathrm{~g}$, while the oil absorbing capacity ranges from 104 to $144 \mathrm{~cm}^{3} / 100 \mathrm{~g}$. The paraffin oil absorption values are significantly higher than the values of water absorption. These values decrease with an increase in the concentration of urea in the reaction mixture as well as an extension of the precipitation process for each of the urea concentrations used.

The analysis of the crystal structure of calcium carbonate precipitated in the presence of urea only indicates the presence of calcite as polymorphic form (Fig. 1). The termal analysis showed a high degree of purity for the calcium carbonate. The microscopic examination showed a smaal proportion of single crystals (Fig. 2). Other crystals were in the form of diverse construction

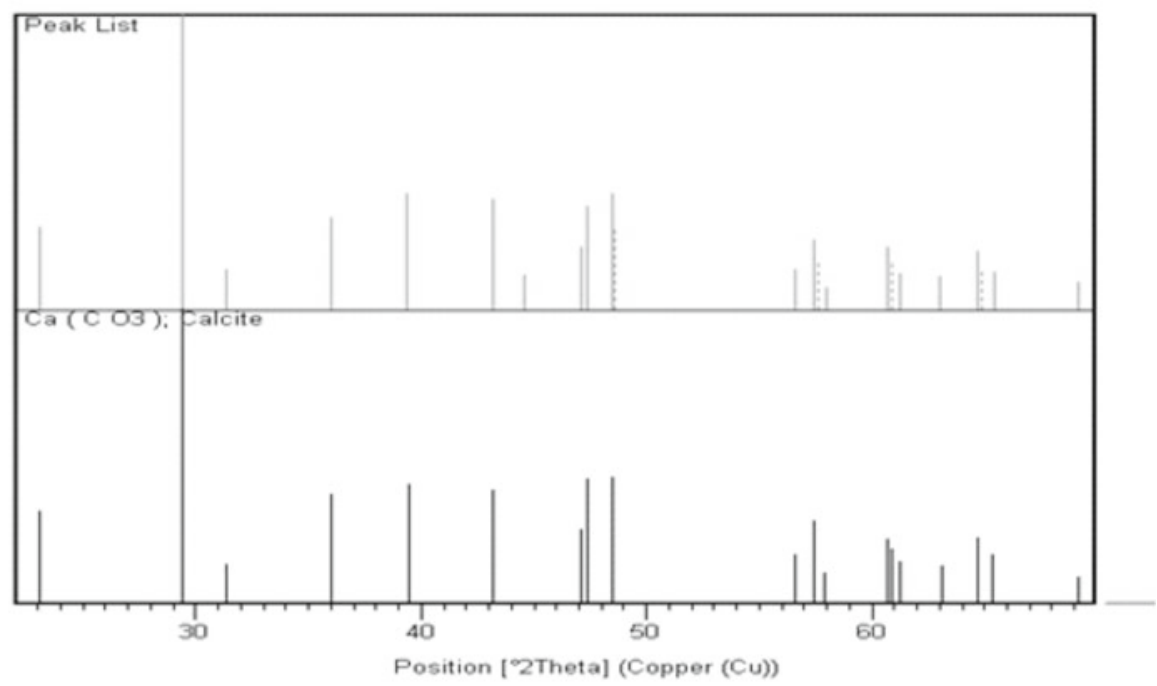

Figure 1. XRD powder pattern of calcium carbonate sample

(A)

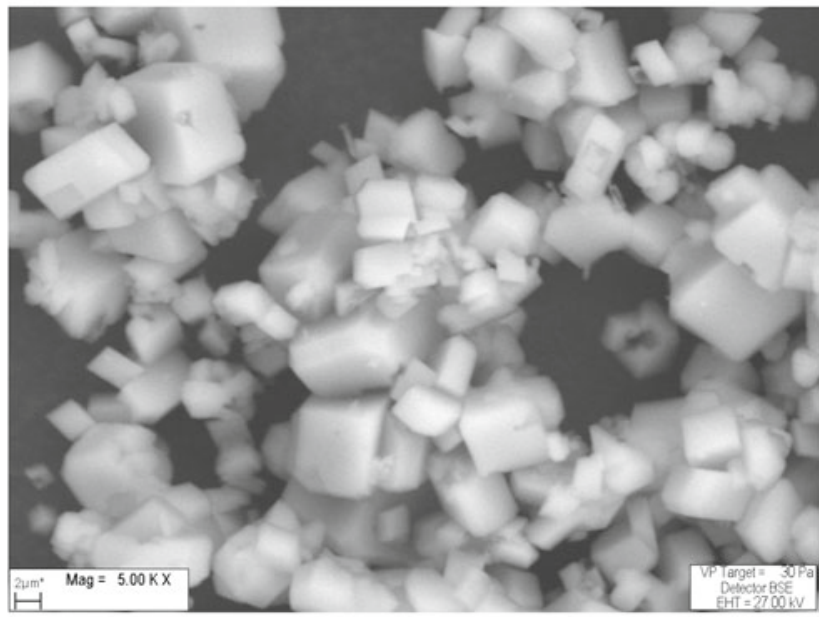

(B)

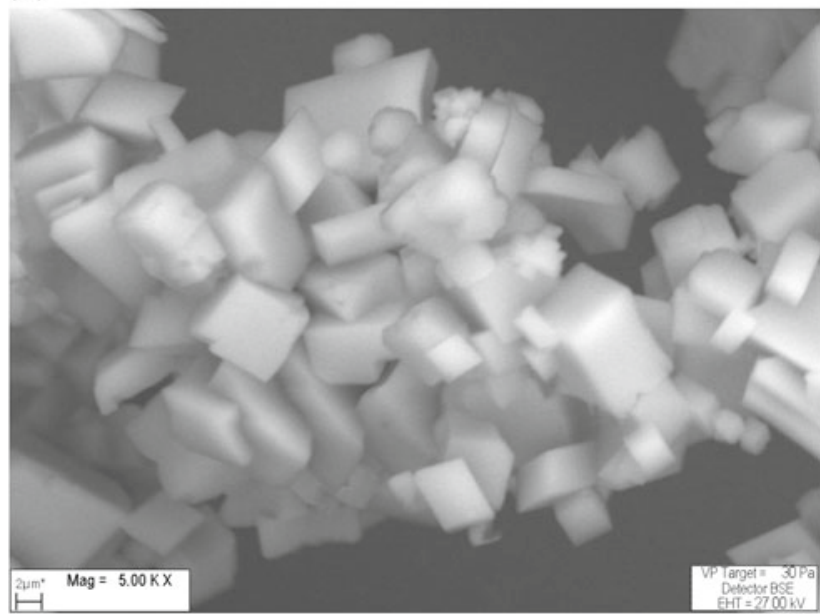

Figure 2. SEM photo of the obtained calcium carbonate sample with the lowest $\left(585 \mathrm{~g} / \mathrm{dm}^{3}\right)(\mathrm{A})$ and highest $\left(909 \mathrm{~g} / \mathrm{dm}^{3}\right)(\mathrm{B})$ packing densities 
conglomerates, with a dominant intermediate geometrical arrangement of the agglomerates. The samples characterized by a higher packing density showed a compact or intermediate geometrical arrangement of the conglomerates and a crystal size of less than $8 \mathrm{~mm}$. The intermediate form of the conglomerates dominates in samples with a lower bulk and packing density. The compact form of the conglomerates was observed only in those samples with a packing density of more than $800 \mathrm{~g} / \mathrm{dm}^{3}$.

\section{CONCLUSIONS}

$\mathrm{CaCO}_{3}$ from the a waste post-distillation liquid (DS) and a sodium bicarbonate saturated solution - both from the Solvay method - in the presence of urea at 293 and $343 \mathrm{~K}$ was obtained. The product obtained in the presence of urea at high concentrations $(5-10 \mathrm{~mol} /$ $\mathrm{dm}^{3}$ ) is characterized by a very low packing density, not exceeding $1000 \mathrm{~g} / \mathrm{dm}^{3}$. Analysis of data reveals that for each series of experiments the increasing time of the reagents dosage into the urea solutions results in the increase of both bulk and packing densities. Absorption capacities for water and paraffin oil decrease with the increasing values of the bulk density.

The increasing urea concentration results in the increase of both bulk and packing densities.

The highest values of the bulk and packing densities are found for $293 \mathrm{~K}$ and $10 \mathrm{M}$ urea solution. $\mathrm{CaCO}_{3}$ obtained for $30 \mathrm{~min}$. time of dosage showed the highest bulk $\left(585 \mathrm{~g} / \mathrm{dm}^{3}\right)$ and packing $\left(909 \mathrm{~g} / \mathrm{dm}^{3}\right)$ densities. For this sample, the absorption capacities of water and paraffin oil are the lowest.

Formation of agglomerates and only small amount of single crystals was observed. Calcite structures of the crystals were evidenced by XRD and SEM.

\section{LITERATURE CITED}

1. Białowicz, K., Trypuć, M. \& Kiełkowska, U. (2010). Precipitation of calcium carbonate from distillation residues and a filtrates from the Solvay process at 293 K. Part 1. Processing of concentrated solutions. Przem. Chem. 89 (1), 72-76.

2. Białowicz, K. (2010). Precipitation of calcium carbonate from distillation residues and a filtrates from the solvay processat 293 K. Part 2. Processing of diluted solutions. Przem. Chem. 89 (1), 77-80.

3. Trypuć, M. \& Białowicz, K. (2010). Precipitation of calcium carbonate from post-distillation liguid and post-filtration liquid from Solvay process in the presence of $\mathrm{CaCO}_{3}$ crystals. Przem. Chem. 89 (10), 1357-1360.

4. Trypuć, M. \& Białowicz, K. (2011). $\mathrm{CaCO}_{3}$ production using liquid waste from Solvay method. J. Clean. Product. 19, 751-756. DOI: 10.1016/j.jclepro.2010.11.009.

5. Białowicz, K. \& Trypuć, M. (2011). Effect of Rosulf an L and Sulforokanol L225/1 on calcium carbonate properties. Przem. Chem. 90 (1), 148-152.

6. Białowicz, K. \& Trypuć, M. (2011). Influence of precipitation conditions on the $\mathrm{CaCO}_{3}$ properties obtained from after distillation liquid and post - filtration liquid of Solvay method at 313 K. Przem. Chem. 90 (8), 1604-1607.

7. Mazurek, K. (2012). Studies on the optimum conditions for leaching the spent vanadium catalyst from metallurgical plants with sodium hydroxide solutions. Przem. Chem. 91 (2), 234-238.

8. Mazurek, K. (2009). Research on the development of optimal parameters of potassium compounds leaching from spent catalysts used for oxidation of sulfur(IV) oxide. Przem. Chem. 88 (9), 1033-1036.
9. Mazurek, K. \& Trypuć, M. (2009). Recovery of the components of the spent vanadium catalyst with sulfuric(VI) acid solutions. Przem. Chem. 88 (11), 1248-1251.

10. Mazurek, K. (2013). Recovery of vanadium, potassium and iron from a spent vanadium catalyst by oxalic acid solution leaching, precipitation and ion exchange processes. Hydrometallurgy 134-135, 26-31. DOI: 10.1016/j.hydromet.2013.01.011.

11. Mazurek, K. (2012). Extraction of vanadium and potassium compounds from the spent vanadium catalyst from the metallurgical plant. Pol. J. Chem. Techn. 14 (2), 49-53. DOI: 10.2478/v10026-012-0070-9.

12. Trypuć, M., Chałat, M., Mazurek K. (2006). Solubility investigations in the $\mathrm{Na}_{2} \mathrm{SO}_{4}+\mathrm{V}_{2} \mathrm{O}_{5}+\mathrm{H}_{2} \mathrm{O}$ system from $293 \mathrm{~K}$ to 323 K. J. Chem. Eng. Data 51 (2), 322-325. DOI: 10.1021/je050233b.

13. Domka, L. (1979). Influence of experimental conditions on the physicochemical properties of precipitated calcium carbonate. UAM, Chemia 33, Poznań.

14. Loy, J.E., Guo, J. \& Severtson, S.J. (2004). Role of Adsorpion Fractionation in Determining the $\mathrm{CaCO}_{3}$ Scale Inhibition Performance of Polydisperse Sodium Polyacrylate. Ind. Eng. Chem. Res. 43, 1882-1887. DOI: 10.1021/ie034078a.

15. Process for the preparation of calcium carbonate, particularly for pharmaceutical - UP - Nr 158809 (UMK).

16. Process for the preparation of technical calcium carbonate - UP - Nr 158672 (UMK).

17. A method for producing calcium carbonate of high packing density - UP - Nr 158673 (UMK).

18. Rai, U.S. \& Rai, R.N. (1996). Studies on physicochemical properties of the eutectic and monotectic in the urea-p. chloronitrobenzene system. J. Cryst. Growth. 169, 563-569. DOI: 10.1016/S0022-0248(96)00448-4.

19. Punin, Y.O. \& Franke, V.D. (1998). Effect of Carbamide Adsorption on the Growth Kinetics of the $\mathrm{NH}_{4} \mathrm{Cl}$ Crystals. Cryst. Res. Technol. 33, 449-455. DOI: 10.1002/(SICI)1521-4079(1998)33:3<449::AID-CRAT449>3.0.CO;2-J.

20. Hong-Kun, Z., Bao-Zeng, R. \& Guo-Ji, L. (2003). Phase Diagram of the System Urea + Hydrogen Peroxide + Water. J. Chem. Eng. Data. 48, 548-550. DOI: 10.1021/je025549n.

21. Sułajmankułow, K. (1971). Sojedinienia karbamidas nieorganitscheskimi soliami. ILIM, Frunze, Russia.

22. Białowicz, K., Trypuć, M. \& Kiełkowska, U. (2008). Precipitation of calcium carbonate in presence of urea. Przem. Chem. 87 (10), 1053-1056.

23. Hermanowicz, W. (1999). Physical-chemical examination of water and wastewater. Arkady, Warszawa.

24. Minczewski, J. \& Marczenko, Z. (1987). Analytical chemistry. PWN, Warszawa.

25. Struszyński, M. (1982). Qualitative analysis and technical. PWT, Warszawa. 